\title{
INFLUENCE OF STRUCTURAL IRREGULARITY IN PLAN FLOOR SHAPE ON SEISMIC RESPONSE OF BUILDINGS
}

\author{
Hamdy H. A. Abd-el-rahim(1) and \\ Ahmed AbdEIRaheem Farghaly ${ }^{(2)}$
}

(1) Associate Professor, Civil engineering department, Assiut University

(2) Lecturer, Faculty of Industrial Education, Sohag University

(Received May 5, 2010 Accepted June 13, 2010)

Buildings with irregularity in plan floors appears to be more susceptible to large deformations and damage when they are subjected to strong ground motion than those with regular plan floors due to the additional accidental torsional forces resulting from the existing eccentricity between the center of mass and center of rigidity of the resisting elements. The evaluation of seismic response of irregular buildings in plan is required in order to determine the seismic level of protection afforded to these buildings by new design provisions which have been introduced to Egyptian code (ECOL201)[15]. Therefore it is intended in the present study to evaluate the performance of gravity loaded irregular buildings in plan under earthquake excitation. The structural irregularities in plan were represented by ten irregular configurations to cover and model the torsional effects. A time history analysis with a peak ground acceleration of $0.25 \mathrm{~g}$ was carried out for these ten models using finite element program SAP2000[16].

The numerical studies for different configurations of irregularity effect were clear in T-plan shape than others. The base shear induced in the perpendicular direction ranged between $40 \%$ and $80 \%$ of the base shear in the direction of the motion. The results declared the necessity of executing structural separation in these irregular buildings in plan to minimize the induced perpendicular base shear. Many conclusions are deduced and they are believed to be very helpful to the structural engineer in order to improve the knowledge of the subject and to avoid unintended consequences of ECOL.

KEY WORDS: seismic response - irregularities - floor plan - top displacement-base shear-time history analysis-torsional effect.

\section{INTRODUCTION}

Possible torsional ground motion, the unpredictable distribution of live load mass and the variations of structural properties are three reasons why both regular and irregular structures must be designed for accidental torsional loads. Also, for a regular structure lateral loads do not excite torsional modes. One method suggested in the Code is to conduct several different dynamic analyses with the mass at different locations. This approach is not practical since the basic dynamic properties of the structure (and the dynamic base shears) would be different for each analysis. In addition, the selection of the maximum member design forces would be a monumental post-processing problem. 
The current Code allows the use of pure static torsional loads to predict the additional design forces caused by accidental torsion. The basic vertical distribution of lateral static loads is given by the Code equations. The static torsional moment at any level is calculated by the multiplication of the static load at that level by 5 percent of the maximum dimension at that level. It is recommended that these pure torsional static loads, applied at the center of mass at each level, be used as the basic approach to account for accidental torsional loads. This static torsional load is treated as a separate load condition so that it can be appropriately combined with other static and dynamic loads.

The effects of coupling between lateral and torsional motions on the earthquake response of asymmetric-plan buildings and how well these effects are represented in seismic codes have been the subject of numerous investigations (Chopra and Goel 1991) [11]. These studies have often led to contradictory conclusions. Elastic response studies showed that the torsional response is pronounced in systems with close torsional and lateral vibration frequencies, which has led to suggestions to increase the design eccentricity from 1 to 1.5 times the static eccentricity to between 3 and 6 times the static eccentricity (Tso and Meng 1982)[12]. In contrast, inelastic response studies showed that the torsional motion is reduced significantly by inelastic action of the system, suggesting that the code values of design eccentricity may require a slight modification, if at all, to be consistent with the dynamic response (Chopra and Goe11991)[11]. As is well known, buildings should be designed to resist moderate ground motion without structural damage and to resist strong ground motion with controlled damage; the former criteria is known as the serviceability limit state and the latter as the ultimate limit state. Therefore, the code design procedures for asymmetricplan systems should be evaluated by simultaneously investigating their elastic response to moderate ground motion, and their inelastic response to intense ground motion. This investigation is a first step towards filling this need. The response of one-storey, asymmetric-plan buildings, designed according to torsional provisions of the U.S. seismic codes (UBC 1990; UBC 1991) [13] [14] to moderate and intense ground motions is investigated. The response of systems designed for the ultimate limit state or serviceability limit state to both ground motions is investigated. Subsequently, the response of buildings designed by the dual design approach, wherein the building is designed for the larger of the forces due to the two limit states, is investigated. Based on these results, shortcomings of the code provisions are identified. In order to alleviate these shortcomings in seismic codes, an extended dual-design approach is proposed, wherein not only the design earthquake but also the values of design eccentricity are defined differently for the two limit states. It is demonstrated that the extended dual-design approach leads to asymmetric-plan systems that satisfy the design requirements for moderate as well as strong ground motion.

Plan asymmetric building structures subjected to lateral input ground motions are affected by torsional coupling, i.e. floor rotations in addition to traslations, which generally results in larger lateral forces and deformations experienced by resisting elements (frames, shear walls etc.). Furthermore, for structures designed to undergo inelastic behaviour under strong earthquakes, torsional motions is one of the most frequent cause of severe damage and failure, since they lead to additional displacements and higher ductility demand in resisting elements. 
In earlier investigations, the effects of torsional coupling on seismic response, for both stiffness and mass eccentric systems, have been widely investigated by means of simple one-storey models (e.g. Goel and Chopra 1991, Rutenberg 1998)[9]. They have been considered suitable to clarify the influence of key structural parameters and to carry out design criteria applicable also to some classes of multistory asymmetric buildings. However, simplified models neglect important effects that may influence inelastic behaviour of resisting elements and, in turn, of the entire structure. Namely, resisting elements are assumed to sustain uni-directional horizontal forces only; therefore, no allowance for vertical forces due both gravity loads and vertical input ground motions is usually made (Ghersi and Rossi) [10].

Torsional effects in earthquakes can occur even when the static centers of mass and resistance coincide. For example, ground motion waves acting with a skew with respect to the building axis can cause torsion. Cracking or yielding in a nonsymmetrical fashion also can cause torsion. These effects also can magnify the torsion due to eccentricity between the static centers. For this reason, buildings having an eccentricity between the static center of mass and the static center of resistance in excess of 10 percent of the building dimension perpendicular to the direction of the seismic force should be classified as irregular. The vertical resisting components may be arranged so that the static centers of mass and resistance are within the limitations given above and still be un-symmetrically arranged so that the prescribed torsional forces would be unequally distributed to the various components. Plan configurations such as H-shapes that have a geometrical symmetry also would be classified as irregular because of the response of the wings. Significant differences in stiffness between portions of a diaphragm at a level are classified as irregularities since they may cause a change in the distribution of seismic forces to the vertical components and create torsional forces not accounted for in the normal distribution considered for a regular building.

Where there are discontinuities in the path of lateral force resistance, the structure can no longer be considered to be "regular." The most critical of the discontinuities to be considered is the out-of-plane offset of vertical elements of the seismic-force-resisting elements. Such offsets impose vertical and lateral load effects on horizontal elements that are, at the least, difficult to provide for adequately.

A structure will have the maximum chance of surviving an earthquake, if a) the load bearing members are uniformly distributed; b) all columns and walls are continuous and without offsets from roof to foundation; c) all beams are free of offsets; d) columns and beams are co-axial; e) columns and beams are nearly the same width; f) no principal members change section suddenly; g) the structure is as continuous and monolithic as possible. Some simple rules for vertical frames in a seismic buildings. If at all un-symmetry is unavoidable, then seismic joints should be provided between them. Seismic joints are special joints designed to prevent hammering of adjacent dissimilar structures, and depends on the relative displacement of floors known as "Drift".

\section{FLOOR PLAN VARIABLES}

This research is restricted to buildings with irregular rectangular floor plan shapes in reinforced concrete frame structures. The term rectangular identifies shape 
characterized by polygons with reentrant corners whose sides meet orthogonally (figure 1).

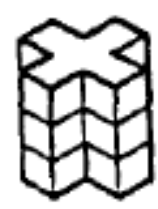

(a) Symmetry

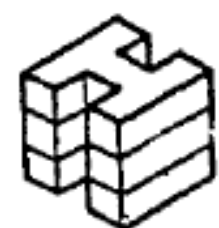

(b) Proportion

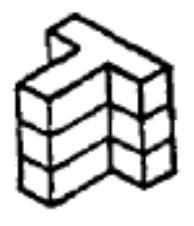

(c) Reentrant corners

Figure 1: Irregular rectangular floor plan shapes

In this study the main variables that define the characteristics of floor plans are: (a) Symmetry, (b) proportion, and (c) reentrant corners. However, even when buildings have floor plan shapes which belong to the same family (i.e. all those in the $\mathrm{H}$ shape family), they do not necessarily possess the same degree of vulnerability to earthquakes. The vulnerability will depend on:

(i) Proportions of the rectangular components of the floor plan shape

(ii) The location within the figure of reentrant corners

(iii) The number of axes of symmetry

(iv) The displacement of corners of rigidity in relation to the center of mass (torsional eccentricity)

Structural asymmetry leads to eccentricity and hence to torsional effects which are induced when the center of rigidity dose not coincide with the center of mass. The building then rotates about its rigidity instead of its center of mass. When this rotation occurs, the weakest elements fail and the building might collapse. The more eccentricity (distance between the center of rigidity and the center of mass), the greater the twisting or torsional effect on the building and, hence, the greater damage.

The length to depth ratio is not related to the dimensions of the rectangular floor plan but in the case of irregular rectangular shapes the ratio of length to depth in each wing (i.e. long wings induce serious diaphragm deformations which lead to torsional effect). Under the action of earthquake forces, each wing will have different dynamic behavior because of its particular stiffness and position relative to the direction of horizontal forces. The movement of the different parts of the building can be very complicated, producing considerable diaphragm deformation, torsional effects and concentration of stress at the vertices of reentrant corners.

Other factors that influence the response of buildings to earthquake forces such as the mass of the building, the materials used, the structural system, and variations in the elevation geometry, the floor plan shape affects the system and variations in the elevation geometry, the floor plan shape affects the destitution of the torsional effects in a significant way. When a poor choice of geometric parameters for a floor plan shape is combined with other inadequate earthquake resistance design features, the vulnerability of the building could be increased and the total effect could be disastrous.

\section{REVIEW OF PREVIOUS STUDIES}

Chandler et al. [1] conclude that all codes satisfactorily control the ductility demand for the flexible-edge element in torsionally unbalanced structures, and that the element 
deformation demand has a consistent relationship with variations of lateral period and static eccentricity, for all the codes considered. For the stiff-edge element in torsionally unbalanced systems, the previously noted deficiencies of codes which permit large reductions of design strength for this side of the structure have been confirmed by the presentation of some key results.

The inelastic torsional behaviour of reinforced concrete (RC) asymmetric buildings using idealized one-storey models was studies by Dutta [2]. He observed that these characteristics may largely magnify the displacement and ductility demand in structural elements due to successive localized unsymmetrical yielding and progressive strength deterioration; resulting in continuous shifting of the centre of strength and thereby increasing strength eccentricity. This magnification effect is generally found to be increasing with the rate of strength deterioration. This effect is not recognized in numerous studies on inelastic behavior of asymmetric buildings as these studies considered bilinear hysteretic behavior devoid of strength deterioration characteristics for lateral load-resisting elements; and as a consequence comparatively lower displacement and ductility demand in load-resisting elements were observed. While using the results of existing literature on inelastic seismic torsional behavior of asymmetric buildings to predict the behavior of RC asymmetric buildings, this limitation should seriously be considered.

Tremblay and Poncet [3] tested an eight - storey concentrically braced steel frame with different setback configurations resulting in sudden reductions in plan dimensions and seismic weight along the height of the structure. Three locations of mass discontinuity were considered $(25 \%, 50 \%$, and $75 \%$ of the building height), together with two ratios of seismic weight (200\% and 300\%). A reference regular structure was also considered for comparison. The design of each structure was performed according to the proposed 2005 National Building Code of Canada NBCC [18] provisions using two analysis methods: The equivalent static force procedure and the response spectrum analysis method. Although severe, the mass irregularity conditions considered in this study were found to have a limited negative impact on the seismic performance of the structures designed with the static analysis method. The performance of irregular structures exhibiting lower performance could be improved by using the dynamic analysis method in design, but not to the level achieved by the reference regular structure

Athanassiadou [4] designed Two ten-storey two-dimensional plane frames with two and four large setbacks in the upper floors respectively, as well as a third one, regular in elevation, to the provisions of the 2004 Euro code 8 (EC8) [19] for the high (DCH) and medium (DCM) ductility classes, and the same peak ground acceleration (PGA) and material characteristics. All frames have been subjected to both inelastic static pushover analysis and inelastic dynamic time-history analysis for selected input motions. The assessment of the seismic performance is based on both global and local criteria. It is concluded that the effect of the ductility class on the cost of buildings is negligible, while the seismic performance of all irregular frames appears to be equally satisfactory, not inferior to (and in some cases superior than) that of the regular ones, even for motions twice as strong as the design earthquake. As expected, DCM frames were found to be stronger and less ductile than the corresponding DCH ones. The over strength of the irregular frames was found to be similar to that of the regular ones, 
while DCH frames are found to dispose higher over strength than DCM ones. Pushover analysis seems to underestimate the response quantities in the upper floors of the irregular frames.

De la Llera et al. [5] Studied the inelastic seismic behavior and design of asymmetric multistory buildings emphasizing, primarily, the use of storey shear and torque histories. The following six different structural characteristics and their effect on the torsional response of buildings are analyzed: strength of orthogonal resisting planes, stiffness asymmetry, strength asymmetry, plan wise distribution of strength, number of resisting planes, and intensity of the ground motion component in the orthogonal direction. As a result of these analyses several techniques and conceptual guidelines were developed to correct the plan wise unbalance in deformation demands typical of asymmetric structures. The two most important are to increase the torsional capacity of the system by introducing resisting planes in the orthogonal direction, and to modify the stiffness and strength distribution to localize yielding in selected resisting planes. Using these guidelines the undesirable earthquake response of a very asymmetrical building is effectively corrected by changing slightly the strength of a few key resisting planes. Finally, it is concluded that the use of the storey shear and response histories in conjunction with the corresponding storey yield surfaces is a powerful tool for conceptual understanding of the earthquake behavior of asymmetric structures.

Chandler and Hutchinson [6] present a detailed parametric study of the coupled lateral and torsional response of a partially symmetric single storey building model subjected to both steady state and earthquake base loadings. It is shown that the qualitative effects of the controlling parameters on the maximum translational and torsional responses of the coupled system are not affected by the nature of the loading. The maximum lateral edge displacement of the building arising from the combined response effects is investigated. The related lateral shear forces in vertical resisting elements located on the periphery of the structure may be significantly increased in comparison with the corresponding values for a symmetric building. It is concluded that for particular ranges of the key parameters defining the structural system, typical of the properties of many actual buildings, torsional coupling induces a significant amplification of earthquake forces which should be accounted for in their design.

Hao and Gong [7] analyzed the inelastic response of a one-storey system with two-way eccentricities and subjected to bidirectional spatial earthquake ground motion. 20 sets of bi-directional spatially varying horizontal earthquake ground motion time histories are numerically simulated for the analysis. The simulated motions are compatible individually with Newmark-Hall design response spectrum with 5\% damping and normalized to $0.5 \mathrm{~g}$, and are compatible with an empirical coherency loss function between each other. Ensemble mean responses of the system to 20 sets of ground motions are estimated. Effects of system parameters such as uncoupled torsional-to-lateral frequency ratios, stiffness eccentricities in both directions, as well as the spatial ground motion wave passage effect, on coupled inelastic torsional-lateral responses are investigated. Numerical results are presented in dimensionless form. They are also compared with the code torsional provisions. For comparison purpose, some results obtained with linear elastic analysis are also presented. 
Mario et al. [8] examine effects of the over strength in element cross-sections on the seismic behaviour of multi-storey asymmetric buildings. They showed that, in actual buildings this characteristic, which is sometimes very variable both in plan and along the height of the building may lead to distributions of ductility demands different from those expected according to the results from single-storey models. Consequently, torsional provisions, which aim at reducing ductility demands of single-storey asymmetric systems to those of the corresponding torsionally balanced systems, should be re-checked in light of the behaviour of realistic multi-storey buildings.

\section{DESCRIPTION OF THE STRUCTURAL MODELS}

A twelve stories "+", "H", "T", "L", "上", and "U" shapes floor plan structures (figure 2) were analyzed using SAP2000 program. Additional assumptions were made: a) the dimension of the structural components are constant at all the floor levels and for all analyzed models: (i) girders $25 \times 75 \mathrm{~cm}$ rectangular transverse section; (ii) columns, $90 \times 90 \mathrm{~cm}$ cubic section; (iii) slab, $14 \mathrm{~cm}$ depth. The storey height in all floors is constant $=3 \mathrm{~m}$, and columns span is $6 \mathrm{~m}$ in X-direction and Y-direction, mass is constant and uniformly distributed in the diaphragm. Regarding material characteristics the following values were used: longitudinal elasticity model $2354 \mathrm{kn} / \mathrm{cm}^{2}$ Poisson ratio 0.2 and total weight per floor $7000 \mathrm{kn}$, and seismic zone $2(0.25 \mathrm{~g})$.

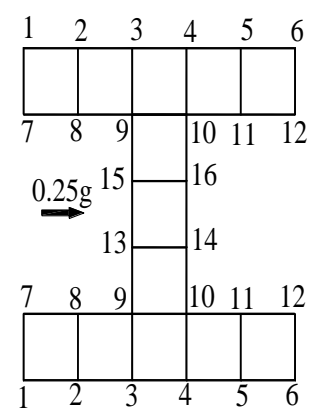

i) I-Shape

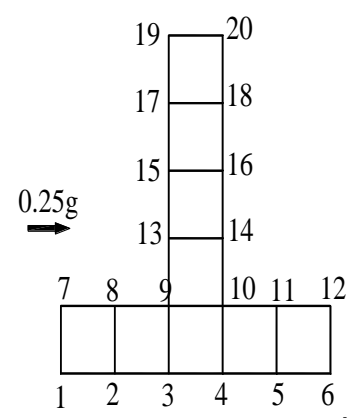

ii) Inverted T-shape" $\perp "$

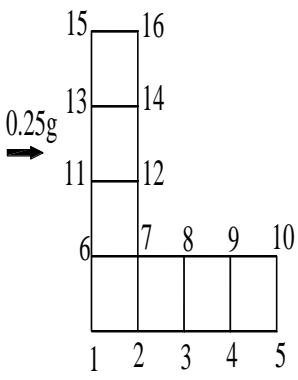

iii) L-Shape

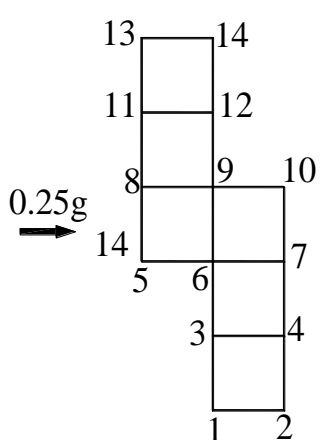

iv) Vertical Z-Shape

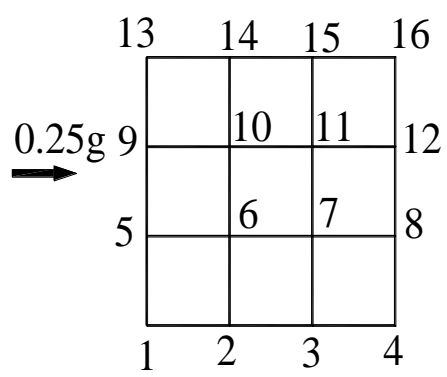

v) Regular Shape

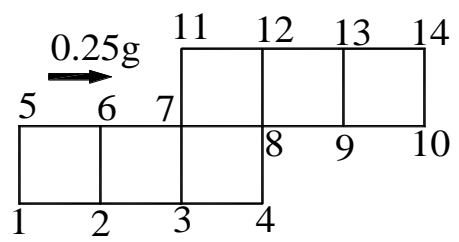

vii) Inverted Vertical Z-Shape Shape

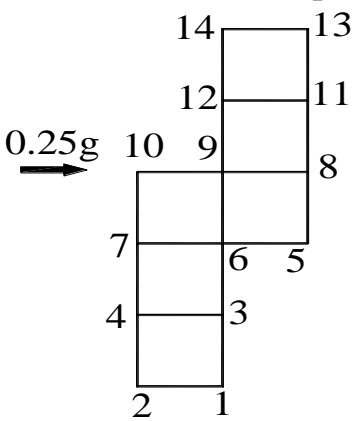

vi) inverted Z- 


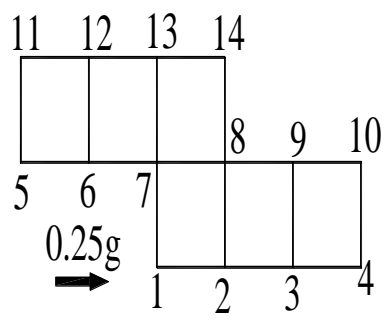

viii) Z-Shape

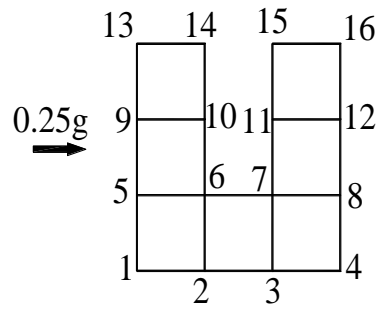

ix) U-Shape

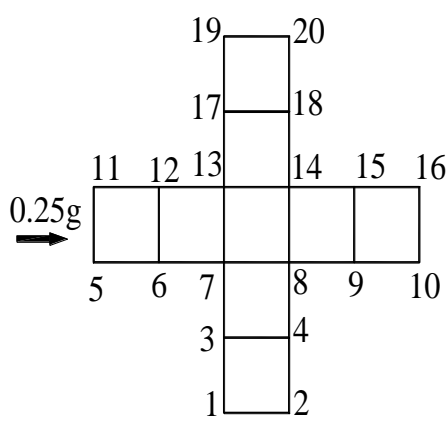

x) +-Shape

Figure 2: Types of irregular plan shapes models

\section{RESULTS AND DISCUSSION}

Many models are tested to show the effect of eccentricity of these irregular plan shapes building subjected to seismic load. The dynamic analysis for each model will be applied by time history analysis using the commercial structural program SAP2000. Four models with irregular plan shape were analyzed to determine the center of mass and center of rigidity then distance between the two centers was been calculated. A regular shape plan building was analyzed for a reference case for the irregular plan shapes buildings. The earthquake direction is in $\mathrm{x}$-direction (uni-directional).

Figure 3 shows the maximum displacements at the top floor of the different types of shape plan. The maximum top displacement appear in the case of "L" and inverted T-plan shape" $\perp$ " nearly $50 \mathrm{~mm}$, the moderate displacement was recorded for "+", "U", "inverted vertical Z", "vertical Z", and regular plan shape nearly $44 \mathrm{~mm}$, and the minimum top displacement was at the case of "I", "inverted Z", and "Z" plan shape nearly $27 \mathrm{~mm}$. The different wings generated by the irregular floor plan will have different dynamic behavior because of their particular geometric and dynamic characteristics and position relative to the direction of the ground motion. The study of buildings that have been subjected to earthquakes has shown that this condition determines an irregular distribution of the lateral force resisting elements proceeding considerable torsional effects and concentration of stress at the vertice of the reentrant corner. Although building damage cannot entirely be attributed to floor plan irregularities this aspect has been acknowledged as one important factor on the response of buildings to earthquake effects. So that buildings with irregular floor plans appear to be more susceptible to larger deformations and damage when subjected to earthquake motions than those with regular floor plans.

As a result of irregularities of the plan shapes of buildings the columns of the buildings subjected to additional base shear represented in a shear force in the perpendicular direction of the earthquake effect.

Figure 4 shows the values and directions of shear forces in the direction of the earthquake effect (X-direction) and in the perpendicular direction (Y-direction). 


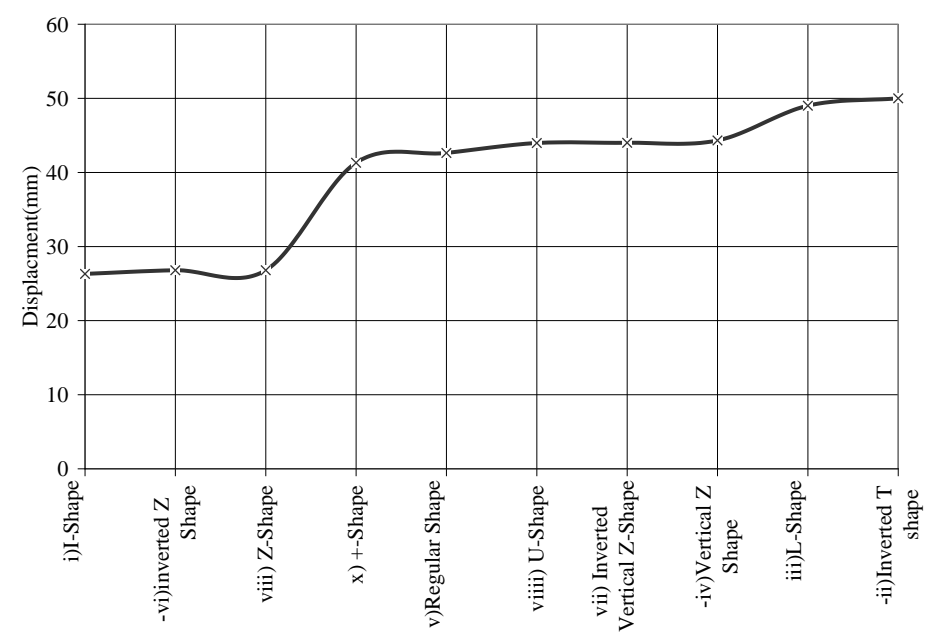

Figure 3: The maximum displacement of top floor for different types of plan shapes

Figure (4-a) shows the base shear in $\mathrm{X}$ and $\mathrm{Y}$ directions on columns for "I" plane shape model. From the figure it can be concluded that the maximum value of the ratio not more $20 \%$ (the base shear in Y direction equal 0.20 of the base shear in Xdirection). These values are not effective on the design of column. The most affected columns were at the middle part of the model and the other columns base shears were almost disappeared. It can be considered that these kinds of buildings are regular plan shape buildings, because of the small values of base shear in Y-direction and the small values of differences between the center of mass and the center of rigidity of each plan shape buildings as shown in table 1 .

Figure (4-b) shows the base shear in $\mathrm{X}$ and $\mathrm{Y}$ directions on columns for " $\perp$ "plane shape model. From the figure it can be recognized that the base shear in $\mathrm{Y}$ direction equal to 0.80 of the base shear in $\mathrm{X}$-direction, the maximum values were appeared at the columns $7,12,1$, and 6 (the corner flange $\perp$ ), this is because of the maximum twist of the model effective on perpendicular of earthquake direction. The exterior corner columns are subjected to larger base shear (Hamdy and Ahmed 2010) [17]. The percentage ratio of base shear for both directions for columns $2,8,11$, and 5 recorded a less value of percentage ratio because it is more near to the middle of the model. All other columns have less percentage ratios values because of the gross values of earthquake force was absorbed by the flange mass of the model.

Figure (4-c) shows the base shear in X and Y directions on columns for "L" plane shape model. From the figure it can be recognized that the base shear in $\mathrm{Y}$ direction equal to 0.65 of the base shear in $\mathrm{X}$-direction, the maximum values were appeared at the columns 5, 6,11, and 13 (5 and 10 are corners columns and 5, 6, and 11 middle exterior columns), this is because of the maximum twist of the model effective on perpendicular of earthquake direction and the resistance of the middle exterior columns with the far corner columns. The base shear for both directions for columns $1,7,9,12,14,8,2,3,4$, and 16 recorded a less values because of its position in the middle of the model far away of the earthquake direction. 
Figures (4-d) and (4-g) show the base shear in $\mathrm{X}$ and $\mathrm{Y}$ directions on columns for vertical $\mathrm{Z}$ and inverted vertical $\mathrm{Z}$ plane shape models respectively. From the figure it can be recognized that the base shear in $Y$ direction equal to 0.03 of the base shear in $\mathrm{X}$-direction, and the maximum values was about $16 \%$. All values nearly equals for each case. The most effective columns were the corners columns (have the most maximum values). The other columns in both models were subjected to small values of base shear in Y-direction (perpendicular direction on earthquake effect).

Figures (4-f) and (4-h) show the base shear in $\mathrm{Y}$ and $\mathrm{X}$ directions on columns for inverted $\mathrm{Z}$ and $\mathrm{Z}$ plane shape models respectively. From the figure it can be recognized that the base shear in $\mathrm{Y}$ direction equal to 0.11 of the base shear in $\mathrm{X}$ direction, and the maximum values was about $21 \%$. All values nearly equals for each case. The most effective columns were the middle exterior columns (i.e. 2, 3, 6, 9, 12, and 13) (have the most maximum values). The other columns in both models were subjected to small values of base shear in Y-direction (perpendicular direction on earthquake effect).

Figure (4-i) describes the base shear in $\mathrm{X}$ and $\mathrm{Y}$ directions for $\mathrm{U}$ plan shape model. The maximum value appear at the exterior corners of columns 1 and 4 (about $38 \%$ ), the columns at the exteriors edges (i.e. 5, 8, 9, 12, 13, and 16) the base shear in $\mathrm{Y}$ direction equals 0.22 the base shear in $\mathrm{X}$ direction which is assumed to be a small ineffective value. It should be noted the resistance of the exteriors columns to the torsion effect of irregularity of the plan shape. It can be considered that these kinds of buildings are irregular plan shape buildings, because of the big values of base shear in Y-direction and the big values of differences between the center of mass and the center of rigidity of each plan shape buildings as shown in table 1 .

Figure (4-j) demonstrates the base shear in $\mathrm{X}$ and $\mathrm{Y}$ directions for " + " plan shape buildings. The values of base shear in Y direction between 0 to \pm 1.6 are small. The maximum values appear at the columns $1,2,6$, and 9 , but the other columns have small values. It can be considered that these kind of buildings a regular plan shape buildings, because of the small values of base shear in Y-direction and the small values of differences between the center of mass and the center of rigidity of each plan shape buildings as shown in table 1 .

Figure (4-e) illustrates the base shear in $\mathrm{X}$ and $\mathrm{Y}$ directions for regular (square) plan shape buildings (control case). This model is a reference (control) model to compare with each model was tested. The values are between 0 and \pm 2 for base shear in Y-direction. The maximum values appear at the columns 2, and 5 (exterior corner columns), but the other columns have a small values. It can be considered that these kind of buildings a regular plan shape buildings, because of the very small values of base shear in Y-direction and the small values of differences between the center of mass and the center of rigidity of each plan shape buildings as shown in Table 1. So, it can be considered that the building is regular if its ratio between bases shears in Y direction (perpendicular to earthquake direction) and base shear in $\mathrm{X}$ direction less than $2 \%$. 


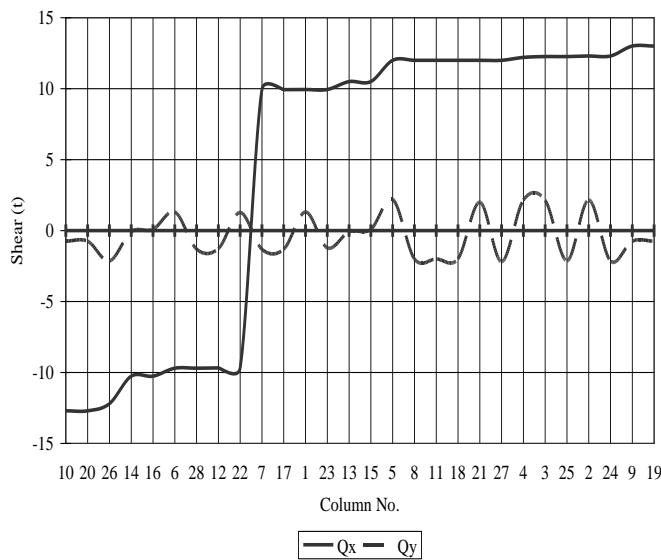

(a) I-plan shape

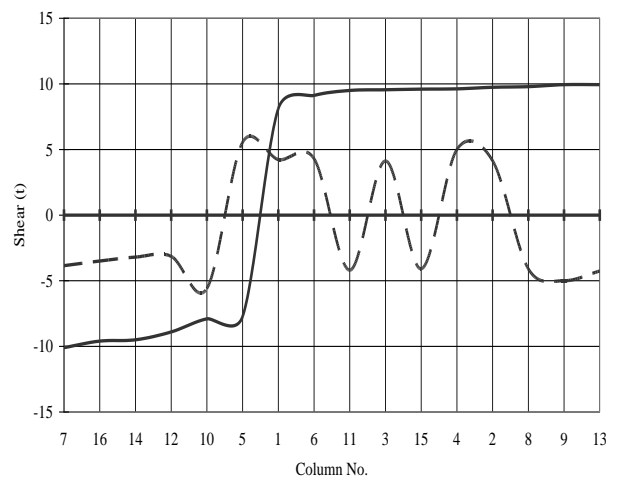

(c) L-plan shape

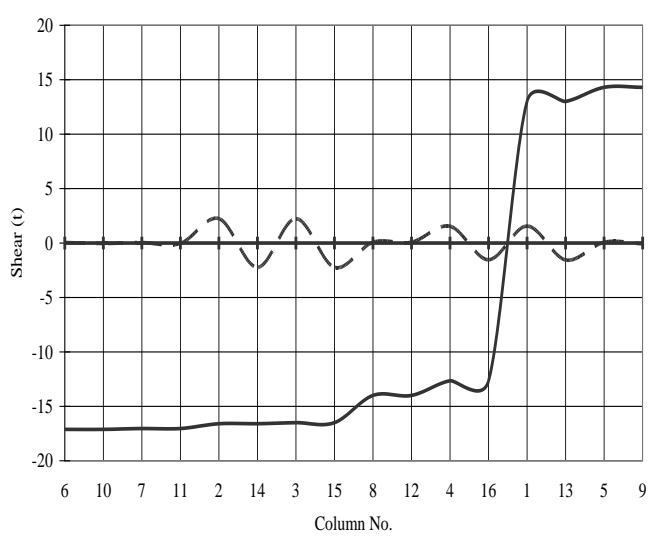

-Qx $-Q y$

(e) Regular (square) plan shape

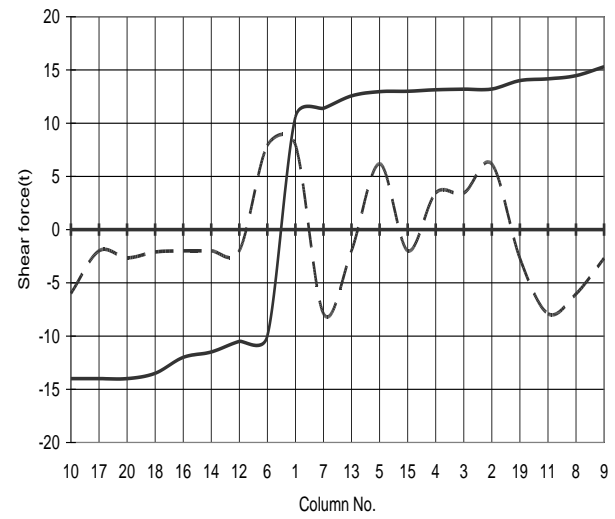

$-a x-a y$

(b) Inverted T-plan shape

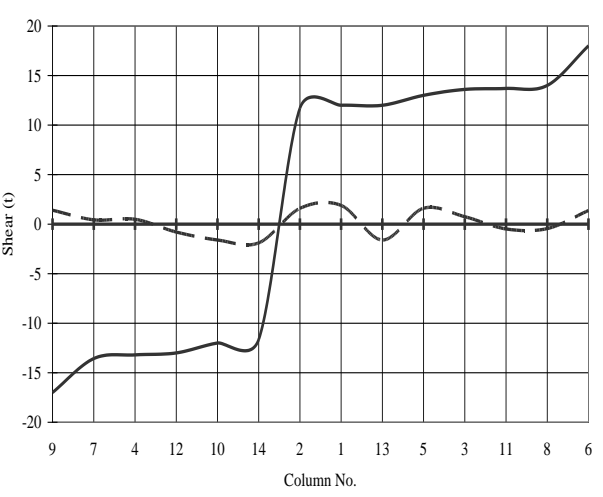

(d) Vertical Z-plan shape

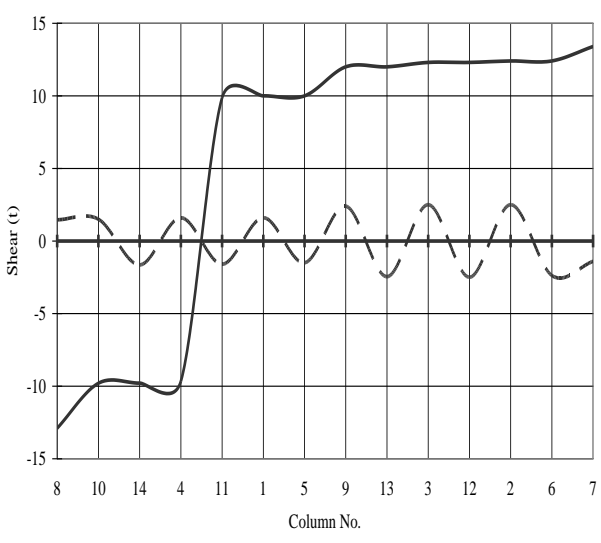

$-Q x-Q y$

(f) Inverted Z-plan shape 


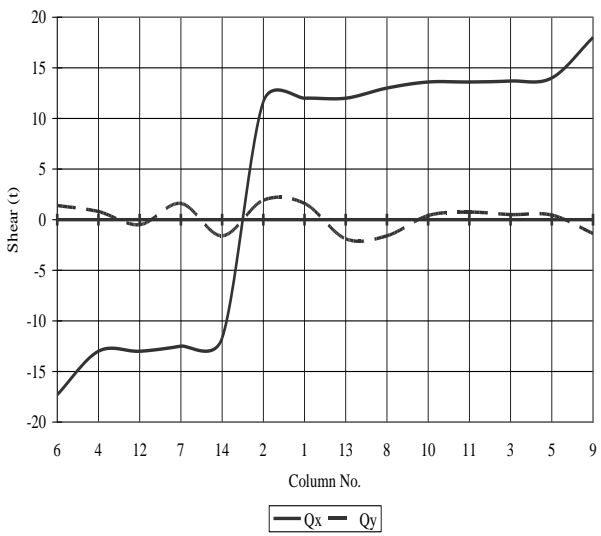

(g) Inverted vertical Z-plan shape

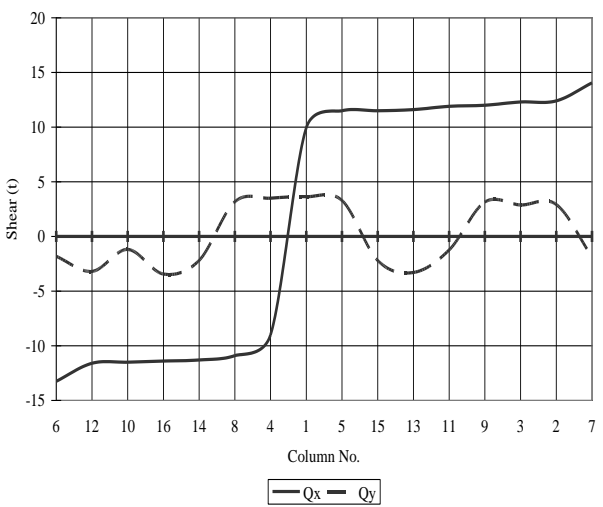

(i) U-plan shape

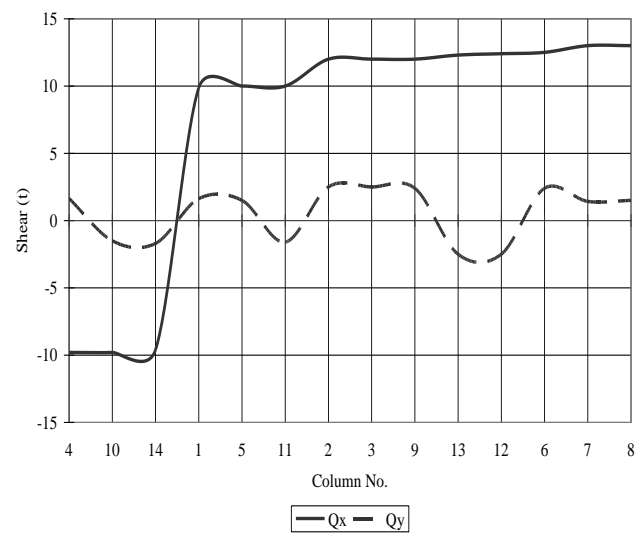

(h) Z-plan shape

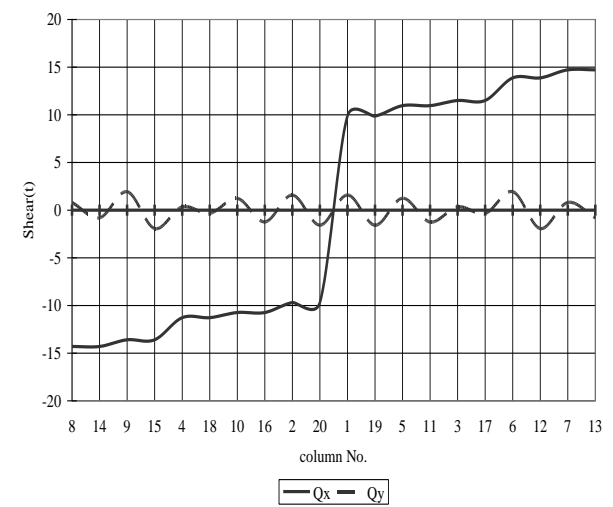

(j) +-plan shape

Figure 4: Values of shear forces in $\mathrm{X}$, and $\mathrm{Y}$ directions for different plan shape buildings

Table (1) shows the differences between the center of mass and the center of rigidity of each plan shape buildings. For "I", "Z", "regular", and "+" plan shape buildings the values of differences between center of mass and center of rigidity in Ydirection not more than $0.01 \mathrm{~m}$, and in X-direction not more than $0.057 \mathrm{~m}$ this indicate small values of base shear force in $\mathrm{Y}$ - direction. " $\perp$ " plan shape building shows a big difference between mass center and rigidity center in y direction leads to a big values of base shear forces in Y-direction as a results of trosional force on the irregularities plan shape, and the maximum ratios between base shear for both directions $\mathrm{X}$, and $\mathrm{Y}$ (base shear in Y-direction equal nearly half the base shear in X-direction). "U" plan shape building shows a big difference between mass center and rigidity center in $\mathrm{y}$ direction leads to a big values of base shear forces in Y-direction as a results of trosional force on the irregularities plan shape, and the maximum ratios between base shear for both directions X, and Y (base shear in Y-direction equal nearly 0.40 the base shear in X-direction). "L" plan shape building shows a big difference between mass center and rigidity center in y direction leads to a big values of base shear forces in $\mathrm{Y}$ direction as a results of trosional force on the irregularities plan shape, and the maximum ratios between base shear for both directions X, and Y (base shear in Ydirection equal nearly 0.30 the base shear in X-direction). 
Table 1: The differences between center of mass and center of rigidity in both $\mathrm{X}$, and $\mathrm{Y}$ directions.

\begin{tabular}{|l|c|c|}
\hline \multirow{2}{*}{ Model } & \multicolumn{2}{c|}{ difference } \\
\cline { 2 - 3 } & $\mathbf{x}(\mathbf{m})$ & $\mathbf{y}(\mathbf{m})$ \\
\hline i)I-Shape & 0.045 & 0 \\
\hline ii)Inverted T-shape " $\perp "$ & 0.040 & 0.874 \\
\hline iii)L-Shape & 0.034 & 0.518 \\
\hline iv)Vertical Z-Shape & 0.04 & 0.005 \\
\hline v)Regular Shape & 0.033 & 0 \\
\hline vi)inverted Z-Shape & 0.055 & 0.001 \\
\hline vii) Inverted Vertical Z-Shape & 0.039 & 0.029 \\
\hline viii) Z-Shape & 0.057 & 0.001 \\
\hline viiii) U-Shape & 0.031 & 0.667 \\
\hline x) +-Shape & 0.047 & 0 \\
\hline
\end{tabular}

\section{CASES OF STUDY " $\perp "$ AND "U" PLAN SHAPES}

To illustrate how to avoid the torsional effect on the irregularity of plan shape of building, two very irregulars cases were studies " $\perp$ ", and "U" plan shape by using time history analysis using program SAP2000. The results of the previous section were analyzed and prove that the maximum values of torsional effect were occurred in these plan shapes so; the suggested solution to reduce this effect by separating the differences parts of building to simple regular plans shapes parts to reduce the effect of torstional shear on each part. Time history analysis was carried on the model to represent the values of base shear in the two directions (direction of earthquake and the perpendicular direction) and the values of maximum top displacement.

Figure 5 shows the separation parts of " $\perp$ " and "U" plans shapes, the" $\perp$ " plan shape separated into two parts A, and B (regular plan shape parts). The "U" plan shape separated to three parts $(\mathrm{A}, \mathrm{B}, \mathrm{C})$ with regular plan shapes.

For figure (5-i) the maximum top displacements values for part (B) (points 13, 14,19 , and 20 ) equals to $4.13 \mathrm{e}-2 \mathrm{~m}$ for all points (the diagram is rigid).

The maximum top displacements values for part (A) (points 1, 6, 7, and 12) equals to $2.5 \mathrm{e}-2 \mathrm{~m}$ for all points (the diagram is rigid).

For figure (5-ii) the maximum top displacements values for parts (A) and (B) equal to $3.85 \mathrm{e}-2 \mathrm{~m}$ for all points (the diagram is rigid). The maximum top displacements values for part (C) equals to $4.13 \mathrm{e}-2 \mathrm{~m}$ for all points (the diagram is rigid). 


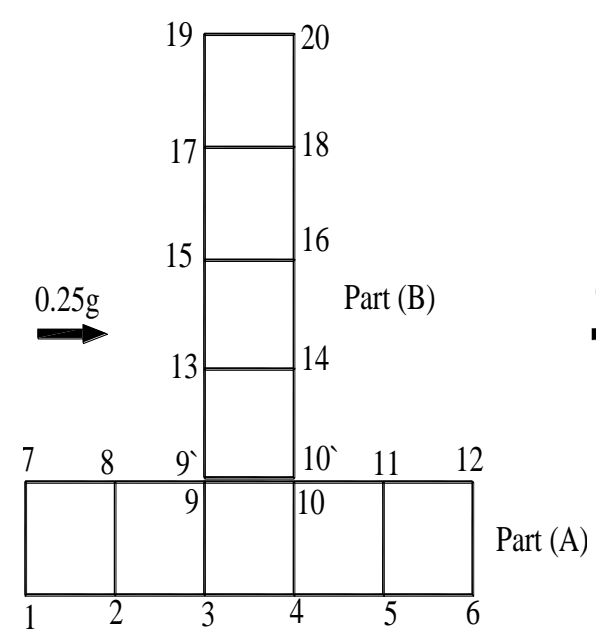

i) The "上" plan shape with two separating parts $(\mathrm{A}, \mathrm{B})$

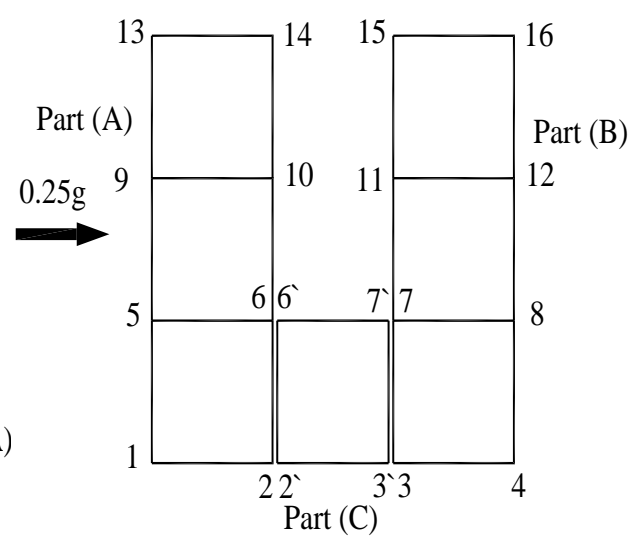

ii) The "U" plan shape with two separating parts $(\mathrm{A}, \mathrm{B}, \mathrm{C})$

Figure 5: The separation parts of " $\perp$ " and "U" plan shapes

The rigidity and the mass centers are coinciding for all parts in the two differences cases of plan shapes for all parts separated.

Figure 6 shows the base shear in X-direction and Y-direction for " $\perp$ " and "U" plan shapes (separated parts).

Figure (6-i) illustrates the base shear in X-direction and Y-direction for "上" plan shapes (separated parts). All values of base shear in Y direction are less than 1.8t.

Figure (6-ii) describes the base shear in Y-direction and X-direction for "U" plan shapes (separated parts). All values of base shear in Y direction are less than $2 \mathrm{t}$.

The values of base shear in $\mathrm{Y}$ direction (the effect of torsion force is small) for the above two models are small compared with the values if the whole plan shape analyzed.

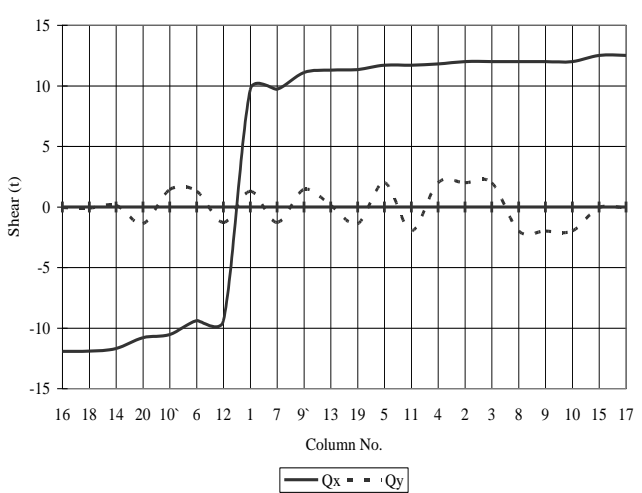

i) Base shear in $\mathrm{Y}$ and $\mathrm{X}$ direction for " $\perp$ " plan shape

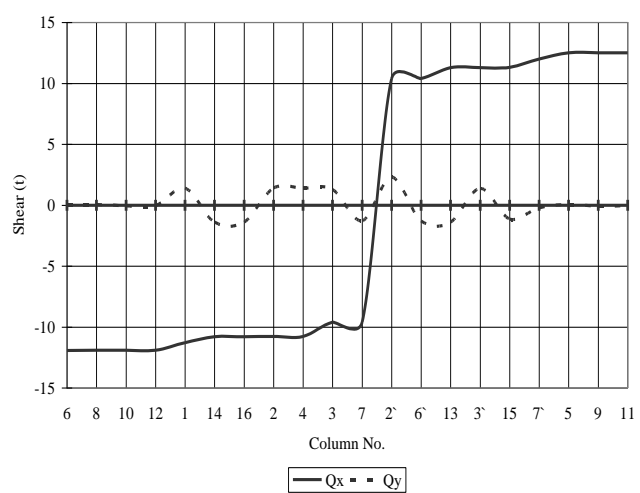

ii) Base shear in $\mathrm{Y}$ and $\mathrm{X}$ direction for "U" plan shape

Figure 6: Base shear in both directions $\mathrm{X}$, and $\mathrm{Y}$

for " $\perp$ " and "U" plan shapes (separated partes) 
Figure 7 demonstrates the base shear in $\mathrm{X}$ and $\mathrm{Y}$ direction for the " $\perp$ " and "U" plan shapes in case of a complete model without separating and with separating parts.

Figure (7-i) illustrates the values of base shear in X direction for " $\perp$ " plan shape with and without separation, it can be seen that the separation did not decrease the base shear in $\mathrm{X}$ direction (earthquake direction). Figure (7-i) shows the values of base shear in $\mathrm{X}$ direction for "U" plan shape with and without separation, it can be seen that the separation did not decrease the base shear in $\mathrm{X}$ direction (earthquake direction).

Figure (7-iii) shows the values of base shear in Y direction for " $\perp$ " plan shape with and without separation, it can be seen that the separation decrease the base shear in $\mathrm{Y}$ direction (perpendicular direction on earthquake direction) with respect to the base shear for plan shape without separation. Figure (7-iv) shows the values of base shear in $\mathrm{Y}$ direction for "U" plan shape with and without separation, it can be seen that the separation decrease the base shear in $\mathrm{Y}$ direction (perpendicular direction on earthquake direction) with respect to the base shear for plan shape without separation.

The separation of irregular plan shape to a regular plan shapes separated parts decreases the effect of torsion force subjected to irregular plan shape building subjected to earthquake.

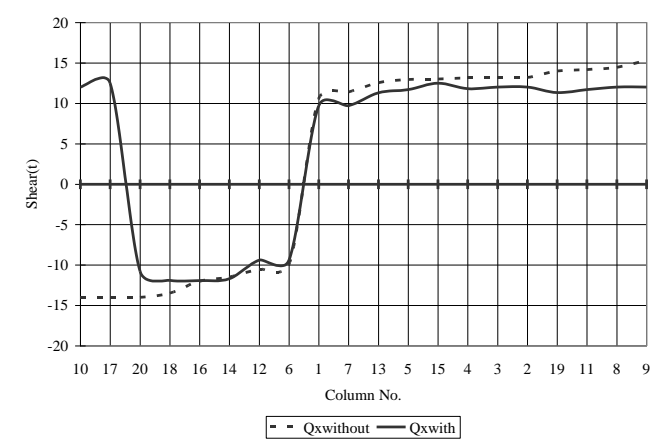

i) Base shear in $\mathrm{X}$-direction for " $\perp$ " plan shape without and with separation

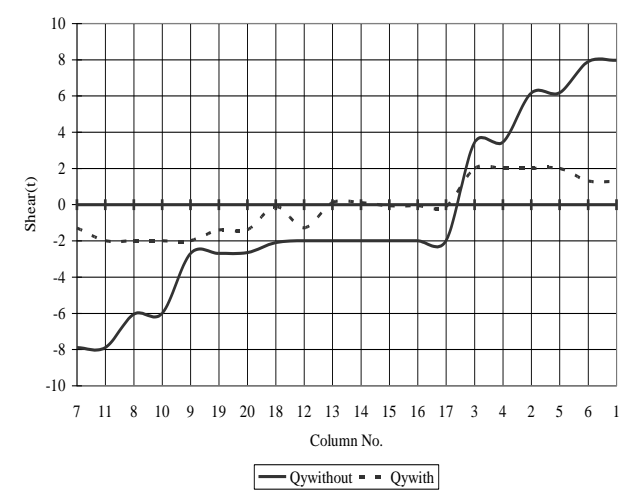

iii) Base shear in Y-direction for " $\perp$ " plan shape

"U" plan shape without and with separation

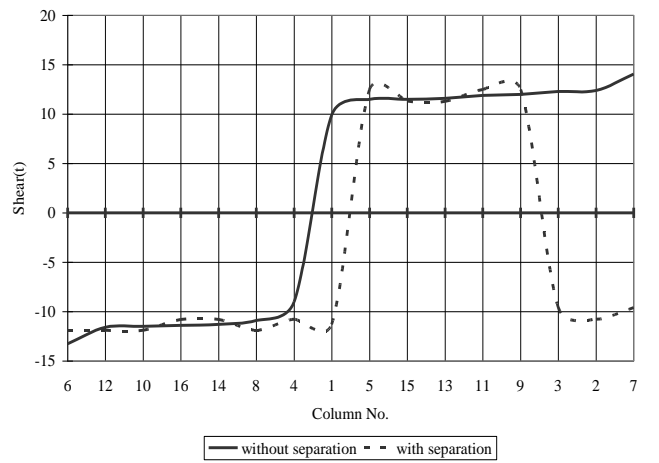

ii) Base shear in X-direction for "U" plan shape without and with separation

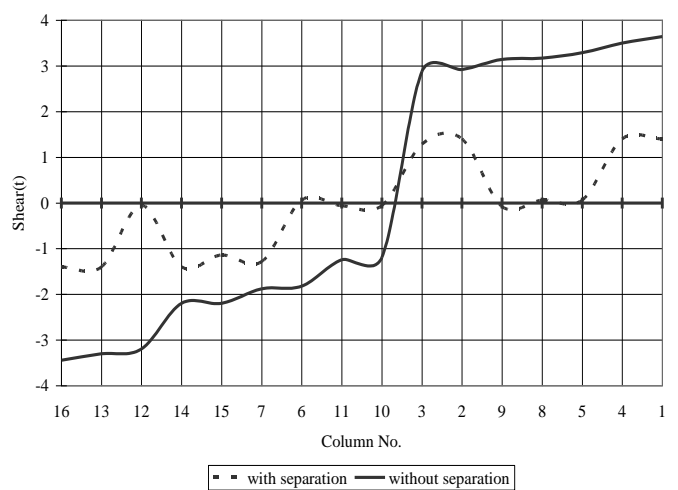

iv) Base shear in Y-direction for without and with separation

Figure 7: Base shear in both directions X, and Y for " $\perp$ " and "U" plan shapes (separated parts and complete shape) 


\section{CONCLUSIONS}

The numerical studies for different configurations of irregularity in plan have been succeeded in identifying the induced additional base shear in the perpendicular direction of the ground motion. The results given in this paper have led to the following conclusions:

- Disadvantages of structural irregularity in plan of building under seismic loads are clear exemplified in T-plan floor shape in comparison with L and U-shape.

- The induced base shear perpendicular to the earthquake direction is sensitive to the torsional eccentricity and increases by about $80 \%, 65 \%$, and $40 \%$ of the base shear in earthquake direction for $\mathrm{T}, \mathrm{L}$, and $\mathrm{U}$ shape respectively.

- Buildings with structural irregularity in plan are insured by imposing structural separation since it results in reducing the perpendicular base shear to the earthquake direction.

- Building irregularity in plan floor has enormous effect on the top displacement of such buildings. The top displacements for $\mathrm{T}$ and $\mathrm{L}$ models are increased up to 1.9 time top displacement in I-model.

\section{REFERENCES}

[1] A. M. Chandler, J. C. Correnza, G. L. Hutchinson "Influence of accidental eccentricity on inelastic seismic torsional effects in buildings" Engineering Structures, Volume 17, Issue 3, April 1995, Pages 167-178

[2] Sekhar Chandra Dutta "Effect of strength deterioration on inelastic seismic torsional behaviour of asymmetric RC buildings"Building and Environment, Volume 36, Issue 10, December 2001, Pages 1109-1118

[3] Robert Tremblay and Laure Poncet "Seismic Performance of Concentrically Braced Steel Frames in Multistory Buildings with Mass Irregularity",J. Struct. Engrg. Volume 131, Issue 9, pp. 1363-1375 (September 2005)

[4] Athanassiadou C. J.,"Seismic performance of R/C plane frames irregular in elevation", Elsevier, Amsterdam, PAYS-BAS (1978) (Revue), 2008, vol. 30, n5, pp. 1250-1261 [12 page(s) (article)] (15 ref.)

[5] Juan C. De la Llera, A.M.ASCE, and Anil K. Chopra, M.ASCE,"Inelastic Behavior of Asymmetric Multistory Buildings", Journal, Vol. 122, No. 6, June 1996, pp. 597-606, (doi 10.1061/(ASCE)0733-9445(1996)122:6(597))

[6] A. M. Chandler, and G. L. Hutchinson "Torsional coupling effects in the earthquake response of asymmetric buildings", Engineering Volume 8, Issue 4, October 1986, Pages 222-236

[7] H. Hao and L. Gong, "Inelastic Response of One-Storey Asymmetric Systems to Bi-directional Spatial Earthquake Ground Motions"

[8] Mario de Stefano, Edoardo Michele Marino, and Pier Paolo Rossi "Effect of Over strength on the Seismic Behavior of Multi-Storey Regularly Asymmetric Buildings", Bulletin of Earthquake Engineering (2006) 4:23-42 Springer 2006

[9] Goel, R.K. \& Chopra, A.K. 1991. Inelastic seismic response of one-storey, asymmetric-plan systems: effects of system parameters and yielding. Earthquake Engineering and Structural Dynamics, 20, 201-222. 
[10] Ghersi, A. \& Rossi, P.P. 1998. Behaviour of in plan irregular buildings subjected to bi-directional ground motions. Proc. of the 11th European Conference of Earthquake Engineering, Balkema, Rotterdam.

[11] Chopra, A. K., and Goel, R. K. (1991). "Evaluation of torsional provisions in seismic codes." Journal of structural engineering, ASCE, 117(12), 3762-3782.

[12] Tso, W. K., and Meng, V. (1982). "Torsional provisions in building codes." Journal of civil engineering, 9(1), 38-46.

[13] Recommended lateral force requirements and tentative commentary. (1990). Structural engineering Association of California, San Francisco, California.

[14] Uniform Buildings Code. (1991). International conference of building officials, Whittier, California.

[15] "The Egyptian Code for Calculation of loads and Forces in Structural Building Work, ECOL 201" Housing and Building Research Center, Cairo, Egypt, September 2008.

[16] "SAP200, Nonlinear version11, Static and Dynamic Finite Elements Analysis of Structure" Computers\& Structures, Inc., Berkeley, U.S.A., 2007.

[17] Hamdy H. A. Abd-el-rahim, and Ahmed AbdElRaheem Farghaly "Role of shear walls in high rise buildings" journal of engineering sciences, vol.(55) no.1 March 2010.

[18] NBCC (2005). "National Building Code of Canada", National Research Council of Canada, Ottawa, Ontario, Canada.

[19] Eurocode 8 [2003] "Design of structures for earthquake resistance," prEN 19981.

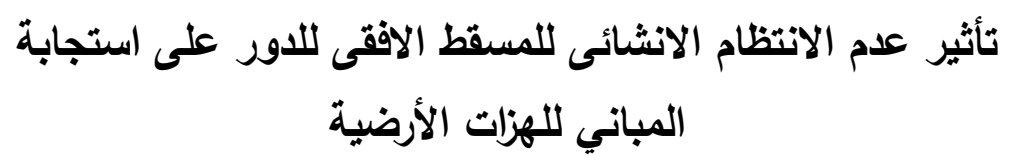

تعد المبانى الغير منتظمة انثائيا فى المسقط الافقى اثد ناثرا للهزات الارضية عن المبانى المنتظمة

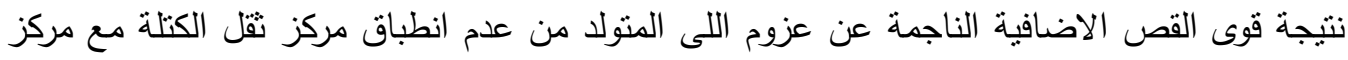

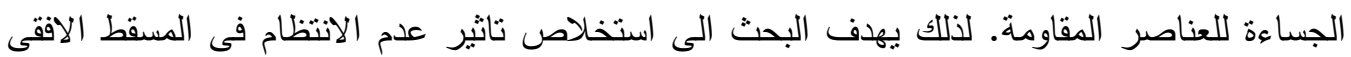

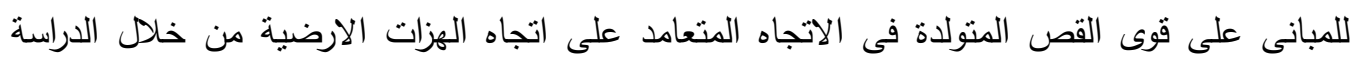

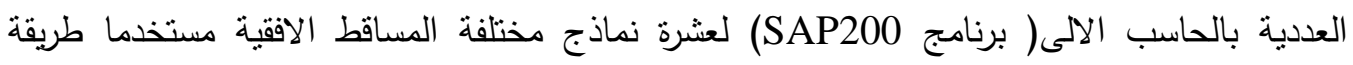

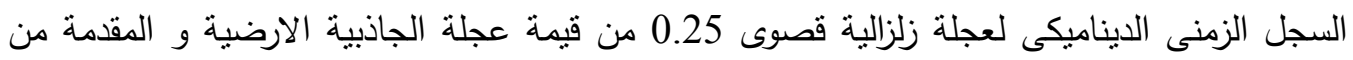

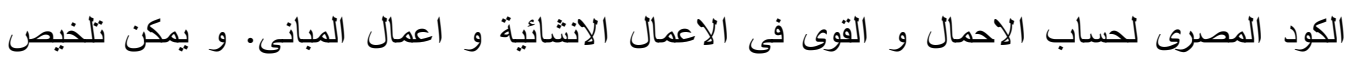

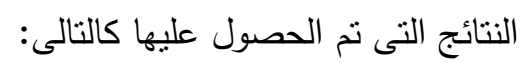

1- عدم الانتظام الانثائى فى المسقط الافقى للمبانى فى هيئة النموذج T ضرب المثل فى وضوح و

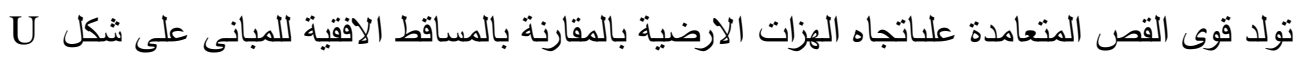

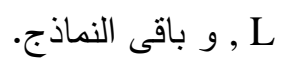


2- قوى القص العمودية المنولدة تعتمد على مقدار اللامركزية لعزوم اللى و تتراوح من 80\% و 65\% و

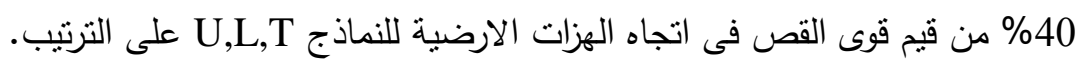

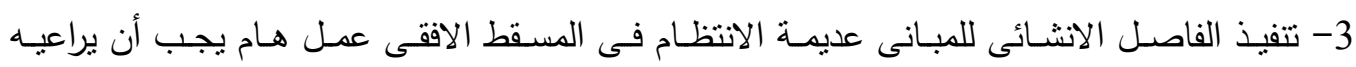
المهندس المصمم لان تتفيذه يؤدى الى اضمحلال قوى القص العمودية على اتجاه القوى الزلزالية لتنأك المبانى. 4- عدم الانتظـام الانثـائى فى المسقط الافقى لـه تـاثير فعـال على مقدار ازاحـة الذروة (العلويـة)

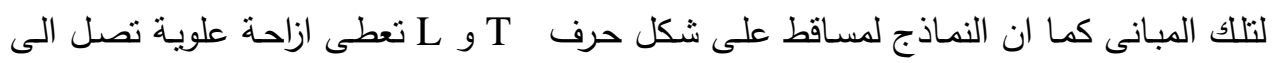

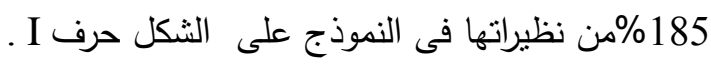

